Journal of Applied

Ecology 2004

41, $72-81$

\title{
Behavioural and environmental correlates of soaring-bird mortality at on-shore wind turbines
}

\author{
LUIS BARRIOS* and ALEJANDRO RODRÍGUEZ† \\ *SEO/BirdLife, Melquíades Biencinto 34, 28034 Madrid, Spain; and †Department of Applied Biology, Estación \\ Biológica de Doñana CSIC, Avda. María Luisa s/n, 41013 Seville, Spain
}

\begin{abstract}
Summary
1. Wind power plants represent a risk of bird mortality, but the effects are still poorly quantified. We measured bird mortality, analysed the factors that led birds to fly close to turbines, and proposed mitigation measures at two wind farms installed in the Straits of Gibraltar, one of the most important migration bottlenecks between Europe and Africa.
\end{abstract}

2. Bird corpses were surveyed along turbine lines and an associated power line to estimate mortality rates. The behaviour of birds observed within $250 \mathrm{~m}$ of turbines was also recorded as a putative indicator of risk. The effects of location, weather and flight behaviour on risk situations (passes within $5 \mathrm{~m}$ of turbines) were analysed using generalized linear modelling (GLM).

3. Mortality caused by turbines was higher than that caused by the power line. Losses involved mainly resident species, mostly griffon vultures Gyps fulvus $(0 \cdot 15$ individuals turbine $^{-1}$ year $\left.^{-1}\right)$ and common kestrels Falco tinnunculus $\left(0 \cdot 19\right.$ individuals turbine $^{-1}$ year $\left.{ }^{-1}\right)$. Mortalities were not associated with either structural attributes of wind farms or visibility.

4. Vulture collisions occurred in autumn-winter and were aggregated at two turbine lines where risks of collisions were greatest. The absence of thermals in winter forced vultures to use slopes for lift, the most likely mechanism influencing both their exposure to turbines and mortality.

5. Kestrel deaths occurred during the annual peak of abundance in summer. Carcasses were concentrated in the open habitats around a single wind farm and risk may have resulted from hunting habitat preferences.

6. Synthesis and applications. We conclude that bird vulnerability and mortality at wind power facilities reflect a combination of site-specific (wind-relief interaction), speciesspecific and seasonal factors. Despite the large number of migrating birds in the study area, most follow routes that are displaced from the facilities. Consequently, only a small fraction of birds on migratory flights was actually exposed to turbines. New wind installations must be preceded by detailed behavioural observation of soaring birds as well as careful mapping of migration routes.

Key-words: bird conservation, flight behaviour, habitat use, migration, wind power

Journal of Applied Ecology (2004) 41, 72-81

\section{Introduction}

Individual-based behavioural models are powerful tools that can predict the response of animal populations to environmental change (Pettifor et al. 2000; Schadt et al.

Correspondence: Alejandro Rodríguez, Department of Applied Biology, Estación Biológica de Doñana CSIC, Avda. María Luisa s/n, 41013 Seville, Spain (fax +34 954621125; e-mail alrodri@ebd.csic.es).
2002). These models rely on fundamental behavioural rules that should remain the same under a variety of circumstances. In order to parameterize these models, there is a need for basic data on the response of animals to anthropogenic structures. Wind farms are such structures whose effects on animals have been particularly neglected. However, the use of wind as a renewable energy source is now increasing in many countries. Wind turbines are often arranged in rows, along coasts or mountain ridges, where soaring birds can use the same air currents 
Bird mortality at wind power plants that lead to the placement of power facilities. As a result, they present a risk to birds of collision or mortality.

It is assumed that wind farms are less harmful to birds than other energy industries or other human-made structures such as power lines (Nelson \& Curry 1995; Osborn et al. 1998), but this belief is based on a limited number of studies. Early research showed that birds collide with turbines and associated power lines (Avery, Springer \& Cassel 1976). Some authors have reported low rates of bird mortality at wind farms (Byrne 1983; Karlsson 1983; Winkelman 1985), whereas others have recorded many casualties involving mainly raptors (Orloff \& Flannery 1992). Moreover, turbines may disturb the foraging and breeding of waterfowl (Winkelman 1989; Pedersen \& Poulsen 1991) resulting in habitat loss (Osborn et al. 1998; Larsen \& Madsen 2000; Guillemette \& Larsen 2002) similar to that caused by road traffic (Gill, Sutherland \& Watkinson 1996).

In order to mitigate bird mortality at wind farms, factors associated with collisions must be identified. Several such factors have been suggested, and include structural and design features of farms and their elements. Lattice towers may be more suitable for perching and thus present more risk than tubular towers (Osborn et al. 1998, 2000). Weather may be important too, and fatalities have been related to poor visibility (Winkelman 1985). The number of casualties also tracks temporal fluctuations in bird abundance and activity (Musters, Noordervliet \& Ter-Keurs 1996; Osborn et al. 1998). Finally, bird habituation to turbines, or hunting and flying at low height near turbines, all might increase mortality (Winkelman 1985; Orloff \& Flannery 1992). Less attention has been paid to habitat use as a factor of risk. Some soaring birds may make intensive use of the mountain ridges where wind turbines are placed, but no explanation has so far been provided for the circumstances in which flying near the ridges increases the risk of collision.

The Straits of Gibraltar are the main point of migratory passage for many soaring birds of the north-west Palaearctic on their journeys between Europe and Africa (Bernis 1962; Moreau 1972; Fernández-Cruz et al. 1990; Finlayson 1992). Several hundred thousand soaring birds cross these straits each year during pre- and postnuptial migrations (Bernis 1980; SEO/BirdLife 2001). The Straits of Gibraltar are included among the four areas in Spain with the greatest potential for producing wind energy (INM 1988; IDAE 1992). Relief and wind are the two principal factors affecting both the behaviour of soaring birds (Ciconiiformes and Falconiformes; Bernis 1962) and the selection of sites for wind farms in this area.

In this study we analysed the effect on soaring birds of the first two wind energy plants ever to be installed in the Straits of Gibraltar. The specific aims were to determine (i) the bird mortality rate associated with wind energy facilities; (ii) the effect of these facilities on bird behaviour and habitat use; (iii) the factors that lead birds to approach the turbines; and (iv) mitigation measures that may reduce avian mortality.

\section{Methods}

\section{STUDY AREA}

The wind farms, called E3 and PESUR, were located in the Campo de Gibraltar region, Cádiz province, Spain (Fig. 1). A series of mountain ranges (maximum altitude $820 \mathrm{~m}$ a.s.1.), running north-south and reaching right to the Straits, divides the region through its centre. Wind farms in this area consist of turbines arranged in rows along the ridges of mountains or hills. In this way, the use of prevailing east-west winds is optimized.

The farm E3 has two rows of 34 and 32 turbines (Table 1) along the ridge of the Sierra de Enmedio, at altitude $420-550 \mathrm{~m}$ a.s.1. $\left(36^{\circ} 05^{\prime} \mathrm{N}, 5^{\circ} 39^{\prime} \mathrm{W}\right)$. East-and west-facing slopes of this range are steep, long and covered with dense scrubland that rarely exceeds $1 \mathrm{~m}$ in height. PESUR has seven turbine rows, each of them with a single type of turbine (Table 1 ). This wind farm is placed in the Dehesa de los Zorrillos $\left(36^{\circ} 03^{\prime} \mathrm{N}\right.$, $5^{\circ} 34^{\prime} \mathrm{W}$ ), on hills with peaks at altitudes of $80-300 \mathrm{~m}$ a.s.l. The vegetation is a mosaic of forest, dense scrubland and pastures. Machines operate at wind speeds between 4.5 and $24 \mathrm{~m} \mathrm{~s}^{-1}$. Both wind farms share a transmission power line (Table 1).

\section{MORTALITY SURVEYS}

The field work was carried out between December 1993 and December 1994. Previously, old bird carcasses were removed from wind farms. Turbine rows were divided into groups of eight (lattice towers) or four (tubular towers) consecutive wind turbines. Fifteen of these groups were chosen randomly as sampling sites. At each sampling site two observers walked thoroughly an area of $50 \mathrm{~m}$ on both sides of the line of turbines looking for dead birds (Winkelman 1985, 1989; Orloff \& Flannery 1992). Searches lasted on average $40 \mathrm{~min}$ per sampling site (range 15-70 $\mathrm{min}$, depending on the vegetation cover). Sampling sites included 87 wind turbines (34\% of all turbines) and seven lattice meteorological towers and lightening conductors. The accessible sections of the power line (six stretches totalling $13 \mathrm{~km}, 54 \%$ of its length) were walked within $25 \mathrm{~m}$ of the line in a zigzag pattern, visiting all pylons in each stretch (Faanes 1987; Negro 1987; Alonso, Alonso \& Muñoz-Pulido 1993).

A preliminary experiment performed in autumn 1993 indicated that more than $20 \%$ of carcasses of domestic pigeon Columba livia Gmelin placed on the ground near turbines disappeared within 4 days. On this basis, the wind turbine sampling areas were visited twice a week and the power line was checked once a week. This search frequency allowed us to estimate the dates of collision. A 100-m wide band along the whole length of both wind farms was surveyed weekly to look for griffon vultures Gyps fulvus Hablizl. Apart from carcasses left in experimental plots to estimate scavenging rates (see 
74

L. Barrios \&

A. Rodríguez
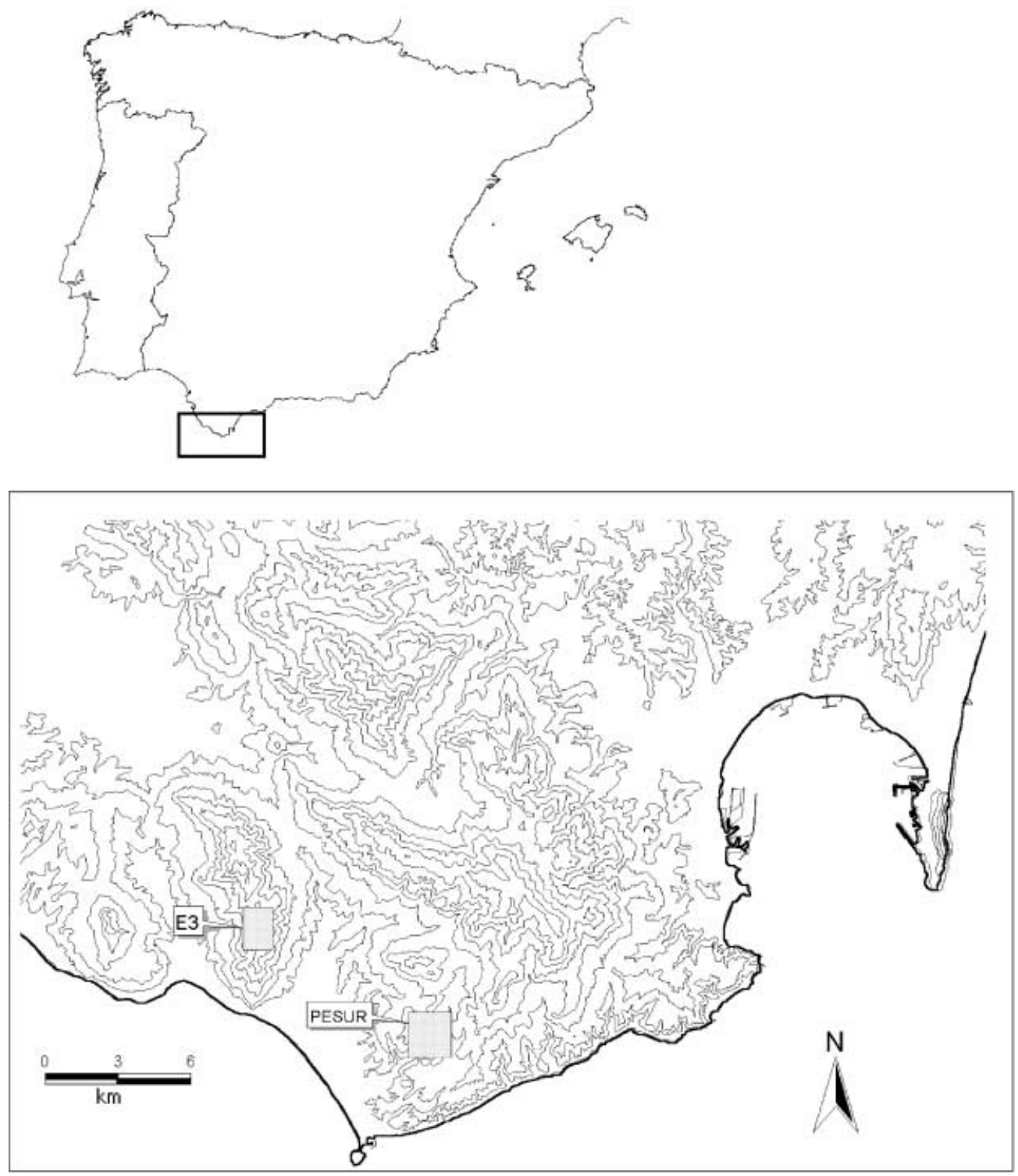

Fig. 1. Location of the Campo de Gibraltar region in the Iberian peninsula, and the study areas on a map showing 100-m altitude contours.

Table 1. Power line and turbine characteristics at PESUR and E3 wind farms, Tarifa, Spain

\begin{tabular}{|c|c|c|c|c|c|c|}
\hline Power line & Length $(\mathrm{km})$ & Voltage (kV) & Insulator configuration & Pylons & \multicolumn{2}{|l|}{ Bird deterrents } \\
\hline & $24 \cdot 4$ & 66 & Suspended* & Lattice & \multicolumn{2}{|c|}{ Wire markers (polypropylene spirals) } \\
\hline \multirow[b]{2}{*}{ Wind farm } & \multicolumn{3}{|l|}{ Turbines } & \multicolumn{3}{|l|}{ Towers } \\
\hline & Number & Power $(\mathrm{kW})$ & Rotor diameter (m) & Type & Height (m) & Spacing $(\mathrm{m})$ \\
\hline \multirow[t]{2}{*}{ PESUR } & 155 & 100 & 18 & Lattice & $18 / 36 \dagger$ & 20 \\
\hline & 35 & 150 & 23 & Tubular & $21 / 28$ & 40 \\
\hline \multirow{2}{*}{ E3 } & 50 & 150 & 21 & Tubular & 24 & 45 \\
\hline & 16 & 180 & 21 & Tubular & 29 & 45 \\
\hline
\end{tabular}

*The least dangerous configuration for birds (Janss \& Ferrer 1999).

$\dagger$ Alternating tower heights in windwall configuration (Orloff \& Flannery 1992).

(C) 2004 British

Ecological Society, Journal of Applied Ecology, 41,

$72-81$ below), all dead birds were removed in order to avoid double counting.

All corpses (whether or not scavenged) and injured birds that showed unequivocal signs of collision (e.g. slice marks) were considered as losses, i.e. birds removed from the population. The following data were recorded for victims of collision: (i) species, age and condition of plumage; (ii) number of turbine, or segment of power 
Bird mortality at wind power plants

line, collided with; (iii) distance and direction of the nearest structure; (iv) meteorological conditions on the days when accidents occurred, recorded at the wind farm; and (v) the time elapsed since the collision, estimated by comparison with dead birds left in experimental plots on known dates.

\section{DETECTABILITY AND DISAPPEARANCE OF BIRD CARCASSES}

Avian mortality rates may be underestimated if not all dead birds are detected or if any corpses are removed by predators (Scott, Roberts \& Cadbury 1972; Faanes 1987; Ferrer, de la Riva \& Castroviejo 1991). In order to account for this bias, correction factors were derived from an experiment aimed at calibrating search efficiency and the amount of time that carcasses remained in the study area. In February 1994, 38 points were chosen randomly within the sampling areas and one dead domestic pigeon was placed at each point. In May and September the experiment was repeated with 37 and 30 pigeons, respectively. Immediately after the pigeons had been distributed by people other than the usual observers, the sampling areas were searched in the normal way. Detected pigeons were recorded and left in the field. Subsequently, all the corpses were visited daily during the first 8 days, and then every other day until they had all disappeared. The time to disappearance was also recorded for two common kestrels Falco tinnunculus L. whose mortality dates were known. In order to estimate the number of pigeon-size birds that were lost between consecutive visits, an exponential function of time was fitted to the data obtained in each season. These functions gave the rate of disappearance for the day $t, f(t)$ :

$$
\begin{aligned}
& f(t)_{\text {winter }}=1.028 \mathrm{e}^{-0.061 t} \\
& f(t)_{\text {spring }}=0.943 \mathrm{e}^{-0.069 t} \\
& f(t)_{\text {summer }}=1 \cdot 154 \mathrm{e}^{-0.212 t}
\end{aligned}
$$
eqn 1 eqn 2 eqn 3

and had very high coefficients of determination (0.93, 0.99 and 0.99 , respectively).

Using equations $1-3$, seasonal correction factors for scavenging (SC) and search success (SS) were calculated as:

$$
\mathrm{SC}=\sum f(t) / T
$$

where $T$ is the number of days elapsed between searches (Ferrer, de la Riva \& Castroviejo 1991), and:

$$
\mathrm{SS}=p(1+q \mathrm{SC})
$$

(C) 2004 British

Ecological Society, Journal of Applied Ecology, 41, $72-81$ where $p$ is the ratio between corpses found and corpses placed in the experiment, and $q=1-p$.

The mortality rate in the season $s, \mathbf{M}_{s}$, was

$\mathrm{M}_{s}=N_{s} /\left(\mathrm{SC}_{s} \mathrm{SS}_{s}\right) E$ where $N_{s}$ was the number of birds found in sampling areas, and $E$ was the sampling effort, i.e. the proportion of turbines searched. The annual mortality rate in each wind farm was calculated as the sum of seasonal mortality rates.

The time to disappearance was recorded for eight griffon vultures with known dates of death. All these carcasses persisted within the sampling area for several months. From this and other evidence (Ferrer, de la Riva \& Castroviejo 1991) we assumed that all birds of the size of a black kite Milvus migrans Boddaert or larger were found. Consequently, for these species correction factors were not used to estimate mortality rates.

\section{BEHAVIOURAL OBSERVATIONS}

Observations were made from the edge of the ridges where rows of turbines were placed, or from sampling areas giving a suitable perspective for estimating the distance between birds and turbines for all types of flights. This distance was estimated using binoculars within $200 \mathrm{~m}$ of the turbines, taking known distances between structures as a reference. A pass was defined as the flight of any soaring bird within $250 \mathrm{~m}$ of a turbine. For each pass we recorded (i) date and time; (ii) which row the turbine was part of; (iii) whether the turbine was rotating; (iv) wind speed and direction, and visibility; (v) height and direction of flight before and during the pass; (vi) type of flight; and (vii) the minimum distance between the bird and the turbine blades.

\section{ANALYSES}

Birds collide with turbines only if they fly close to them. Conceivably, mortality may increase with the frequency of flights in the immediate vicinity of rotating blades. Thus, a putative 'risk situation' occurred when a bird passed within $5 \mathrm{~m}$ of the blades of an operating wind turbine, and we examined the effect on such situations of three explanatory variables.

1. Type of flight was a factor with three levels: (i) straight, birds directly approached a row of turbines and crossed between or over them; (ii) circling, birds made use of the lifts generated in the windward slope in order to gain altitude; and (iii) slope, birds flew parallel to the ridge along the hillside, either gliding or flapping, but without intending to gain altitude.

2. Height at which the bird entered the 250-m sampling strip (above or below the blades).

3. Wind speed at the time of observation, categorized as light, $4 \cdot 6-8 \cdot 5 \mathrm{~m} \mathrm{~s}^{-1}$, moderate, $8 \cdot 6-12 \cdot 5 \mathrm{~m} \mathrm{~s}^{-1}$, and strong, $>12 \cdot 5 \mathrm{~m} \mathrm{~s}^{-1}$.

The occurrence of risk situations was analysed with generalized linear models (GLM) using binomial errors and a logit link (Crawley 1993). The significance of each explanatory variable was assessed in a stepwise forward manner. For each species, and for any combination of wind speed and bird behaviour, the 'risk index' was defined as the frequency of risk situations, i.e. the 
76

L. Barrios \&

A. Rodríguez ratio between the number of birds observed within $5 \mathrm{~m}$ of the blades and the total number of passes or observations within $250 \mathrm{~m}$ of the turbine lines.

\section{Results}

\section{MORTALITY}

During the study year 68 birds collided with the structures. Most dead birds (51) were medium-sized or large species of the orders Ciconiiformes, Falconiformes and Strigiformes, while the remaining 17 individuals were smaller birds (Table 2). In addition, 34 dead birds were found during the survey conducted before the field work. Griffon vulture and common kestrel were most frequently killed (Table 2). The distribution of losses across major taxonomic groups pre-December $1993 \mathrm{did}$ not differ from that during the study period $(G=5 \cdot 29$, d.f. $=3, P=0 \cdot 15)$, even when the griffon vulture was treated as a separate class $(G=6 \cdot 68$, d.f. $=4, P=0 \cdot 15)$.

There were large differences between wind farms in the frequency of casualties. The number of bird losses per turbine and year for E3 was much lower than for PESUR (goodness-of-fit $\chi^{2}=37 \cdot 27$, d.f. $=1, P<0 \cdot 001$; Tables 2 and 3).

There were no visible signs of electrocution on any bird, and all the accidents were attributed to collision with the wind turbines or with the electrical transmission wires.

\section{Griffon vulture}

It was possible to age 35 vultures involved in collisions, five of them found in the preliminary survey. Seven vultures were young-of-the-year, 18 were immatures or subadults, and 10 were adults. All 35 vultures appeared to be healthy as judged from plumage condition and, when possible, fat stores.

The distribution of deaths was not homogeneous throughout the study period. All 30 vultures died between October and April, with $20(66 \cdot 7 \%)$ of the accidents taking place between December and February. There was also a clear spatial aggregation of vulture collisions. At PESUR 16 vultures died in two specific segments of two rows totalling 28 turbines, that is, $15 \%$ of turbines were responsible for $57 \%$ of collisions. It was not possible to identify physiographic differences between the two places where accidents were aggregated and nearby locations where bird mortality was lower. Tower structure could be excluded as a factor as the number of losses in each type of tower $(85 \%$ in lattice towers, $15 \%$ in tubular towers) was not significantly different from their availability (Table $1 ; \chi_{c}^{2}=0 \cdot 18$, d.f. $=1$, $P=0 \cdot 67)$.

Table 2. Total number of recorded bird losses at PESUR and E3 wind farms. Birds found within sampling areas are given in parentheses, except for griffon vultures which were searched across the whole study area

\begin{tabular}{|c|c|c|c|c|c|c|c|c|c|}
\hline \multirow[b]{2}{*}{ Species } & \multicolumn{4}{|c|}{ Study period } & \multicolumn{4}{|c|}{ Before the study period } & \multirow{2}{*}{$\begin{array}{l}\text { Grand } \\
\text { total }\end{array}$} \\
\hline & PESUR & E3 & Power line & Total & PESUR & E3 & Power line & Total & \\
\hline \multicolumn{10}{|l|}{ Falconiformes } \\
\hline Gyps fulvus & 28 & 2 & 0 & 30 & 17 & 2 & 0 & 19 & 49 \\
\hline Falco tinnunculus & $12(8)$ & 0 & 0 & $12(8)$ & 0 & 0 & 0 & 0 & 12 \\
\hline Falco naumanni & $3(0)$ & 0 & 0 & $3(0)$ & 3 & 0 & 0 & 3 & 6 \\
\hline Circaetus gallicus & $2(2)$ & 0 & 0 & $2(2)$ & 0 & 0 & 0 & 0 & 2 \\
\hline Neophron percnopterus & 0 & 0 & 0 & 0 & 2 & 0 & 0 & 2 & 2 \\
\hline Milvus migrans & $1(1)$ & 0 & 0 & $1(1)$ & 1 & 0 & 0 & 1 & 2 \\
\hline Unidentified & $1(1)$ & 0 & 0 & $1(1)$ & 1 & 0 & 0 & 1 & 2 \\
\hline Total & 47 & 2 & 0 & 49 & 24 & 2 & 0 & 26 & 75 \\
\hline
\end{tabular}

Other groups: Strigiformes, 4 (Bubo bubo, Athene noctua); Ciconiiformes, 2 (Ciconia ciconia, Bubulcus ibis); Cuculiformes, 1 (Cuculus canorus); Passeriformes, 20 (Sturnus unicolor, Turdus merula, Miliaria calandra, Carduelis cannabina, Hippolais polyglota, Saxicola torquata, Oriolus oriolus, Lanius senator).

Table 3. Estimated number of bird losses and mortality rates per turbine and year at PESUR and E3 wind farms

(C) 2004 British Ecological Society, Journal of Applied Ecology, 41, $72-81$

\begin{tabular}{|c|c|c|c|c|c|c|}
\hline \multirow[b]{2}{*}{ Species } & \multicolumn{2}{|l|}{ PESUR } & \multicolumn{2}{|l|}{ E3 } & \multicolumn{2}{|l|}{ Total } \\
\hline & Deaths & Mortality rate & Deaths & Mortality rate & Deaths & Mortality rate \\
\hline Gyps fulvus & 28 & $0 \cdot 150$ & 2 & $0 \cdot 030$ & 30 & $0 \cdot 120$ \\
\hline Falco tinnunculus & 36 & $0 \cdot 190$ & 0 & $0 \cdot 000$ & 36 & $0 \cdot 140$ \\
\hline Circaetus gallicus & 2 & $0 \cdot 010$ & 0 & $0 \cdot 000$ & 2 & $0 \cdot 008$ \\
\hline Milvus migrans & 1 & $0 \cdot 005$ & 0 & $0 \cdot 000$ & 1 & $0 \cdot 004$ \\
\hline Unidentified raptor & 1 & $0 \cdot 005$ & 0 & $0 \cdot 000$ & 1 & $0 \cdot 004$ \\
\hline Total & 68 & $0 \cdot 360$ & 2 & $0 \cdot 030$ & 70 & $0 \cdot 270$ \\
\hline
\end{tabular}


Bird mortality at wind power plants
All deaths occurred on clear days except one collision at E3 during a misty day. Owing to the frequent changes in wind direction and speed, even over the course of a single day, it was difficult to be certain of the wind conditions when accidents occurred. Therefore, although 29 vultures were found soon after the collision, the wind force could be determined only in 22 cases (16 birds found within $24 \mathrm{~h}$ after the collision, five found within 3 days and one observed crash). Collisions rarely occurred in strong winds. Only two accidents occurred when wind speed was $>8 \mathrm{~m} \mathrm{~s}^{-1}$ during the entire day. Twelve vultures collided on days when wind speed was $\leq 8 \mathrm{~m} \mathrm{~s}^{-1}$ at least for a few hours, and eight vultures died on days in which wind speed never reached $8 \mathrm{~m} \mathrm{~s}^{-1}$.

Griffon vulture counts over the entire study area were accepted as the actual losses (Table 3 ). The number of dead vultures per turbine and year at PESUR $(0 \cdot 15)$ was five times greater (goodness-of-fit $\chi^{2}=6 \cdot 81$, d.f. $=1$, $P=0.009)$ than at E3 (0.03).

\section{Common kestrel}

The eight common kestrels that could be aged were all juveniles. Deaths were concentrated in summer. Eight birds $(67 \%)$ collided with wind turbines between 15 July and 17 August 1994, the period of the year during which the highest concentration of common kestrels was observed in the region. All dead common kestrels were found at PESUR. Fatalities were evenly distributed across the wind farm, and all occurred in sparsely vegetated areas on days with good visibility. The distribution of collisions between lattice $(75 \%)$ and tubular towers $(25 \%)$ was not significantly different from the availability of each type of tower $(G=0 \cdot 20$, d.f. $=1$, $P=0 \cdot 65)$. Wind speed was known only for five kestrel collisions. Two deaths occurred on days with a strong easterly wind and three with a weak westerly wind. The corrected number of dead kestrels at PESUR was 36 individuals (Table 3 ), translating into a mortality rate of $0 \cdot 19$ common kestrels per wind turbine and year.

\section{WIND, BIRD BEHAVIOUR AND PUTATIVE RISK OF COLLISION}

\section{Griffon vulture}

Out of 14524 bird passes by wind farms, 4809 (33\%) were of griffon vultures. There were seasonal variations in the frequency of passes of griffon vultures and therefore in their exposure to turbines. The resident population consisted of 274 pairs in 1994, corresponding to a density of 34 pairs $100 \mathrm{~km}^{-2}$ (Del Junco \& Barcell 1997). In spring and summer these vultures regularly patrolled ridges and slopes, including those hosting turbines, during their daily movements. After juvenile fledging, the local population reached its maximum levels in autumn-winter. At wind farms, the mean vulture count in spring-summer (120 birds month $\left.{ }^{-1}\right)$ was lower $(t=1.95$, d.f. $=8, P=0.087)$ than in autumnwinter $\left(537\right.$ birds month $\left.{ }^{-1}\right)$. The lack of significance of this comparison was due to a large variance in the autumn samples (10 times higher than in other seasons) associated with large numbers of migrating vultures.

There was a clear seasonal pattern in the risk index. In spring-summer there was little variation around a mean of $0 \cdot 29$ (range $0 \cdot 15-0 \cdot 34$ ) associated with a relatively stable population size. In autumn-winter the risk index fluctuated markedly (range $0 \cdot 04-0 \cdot 76$ ), coinciding with large variations in monthly vulture counts. In other words, both high values of the risk index and a large number of birds (which increases the probability of collision) occurred in autumn-winter.

There was spatial variation in the use of particular mountains. Once corrected for wind farm length, average annual sighting frequencies at PESUR (10 vultures $\left.\mathrm{h}^{-1}\right)$ were higher $\left(\chi_{\mathrm{c}}^{2}=50 \cdot 16\right.$, d.f. $\left.=1, P<0 \cdot 001\right)$ than at E3 (6.5 vultures $\left.h^{-1}\right)$. The frequency distribution of bird distances to the nearest turbine differed between wind farms (Fig. 2; $G=183 \cdot 7$, d.f. $=3, P<$ $0 \cdot 001)$. The proportion of passes within $5 \mathrm{~m}$ of turbines greatly contributed to these differences. Indeed the risk index was 0.198 for PESUR but only 0.059 for E3 $\left(\chi_{\mathrm{c}}^{2}=104 \cdot 9\right.$, d.f. $=1, P<0 \cdot 001$; Fig. 2$)$. Moreover, in the two rows of PESUR where the highest mortality rates were recorded, the number of passes within $5 \mathrm{~m}$ of turbines was twice as high as expected from row length $\left(\chi^{2}=296 \cdot 6\right.$, d.f. $\left.=6, P<0 \cdot 001\right)$.

At wind speeds lower than $4.5 \mathrm{~m} \mathrm{~s}^{-1}$ the turbines did not turn and there was a no-risk situation. When turbines were rotating, the frequency of risk situations at PESUR varied significantly with wind speed $(G=355 \cdot 1$, d.f. $=$ $2, P<0.001)$. The risk index was 0.343 in the range $4 \cdot 6-8 \cdot 5 \mathrm{~m} \mathrm{~s}^{-1}$ and decreased with increasing wind speed (0.195 and 0.037 for moderate and strong winds, respectively). There was also a clear effect of type of flight ( $G=$ $259 \cdot 2$, d.f. $=2, P<0 \cdot 001)$. The risk index was highest $(0 \cdot 279)$ when vultures circled, followed by straight and slope flights $(0 \cdot 131$ and $0 \cdot 032$, respectively). The relative height at which birds entered the 250-m observation strip strongly influenced the frequency of risk situations. The risk index linked to flights of birds coming from above the turbines $(0 \cdot 062, n=2113)$ was much lower $(G=287 \cdot 6$, d.f. $=1, P<0.001)$ than the risk index of birds entering the observation area from below $(0 \cdot 259, n=1719)$. Furthermore, when a bird came below the level of turbines in moderate winds, the risk index was much higher than in strong winds (Fig. 3). This interaction between initial flight height and wind speed was highly significant and remained in the final model (Table 4a).

The effect of wind speed on the frequency of risk situations at E3 was much lower than at PESUR ( $G=$ $5 \cdot 83$, d.f. $=2, P=0 \cdot 05)$. Risk indices at E3 were higher under moderate winds than under light winds ( 0.081 and $0 \cdot 048$, respectively), whereas they were negligible in strong winds (0.008). At E3, straight flights were the most risky $(0 \cdot 065)$, followed by circling $(0 \cdot 040)$ and slope
Journal of Applied

Ecology, 41.

72-81 
78

L. Barrios \&

A. Rodríguez

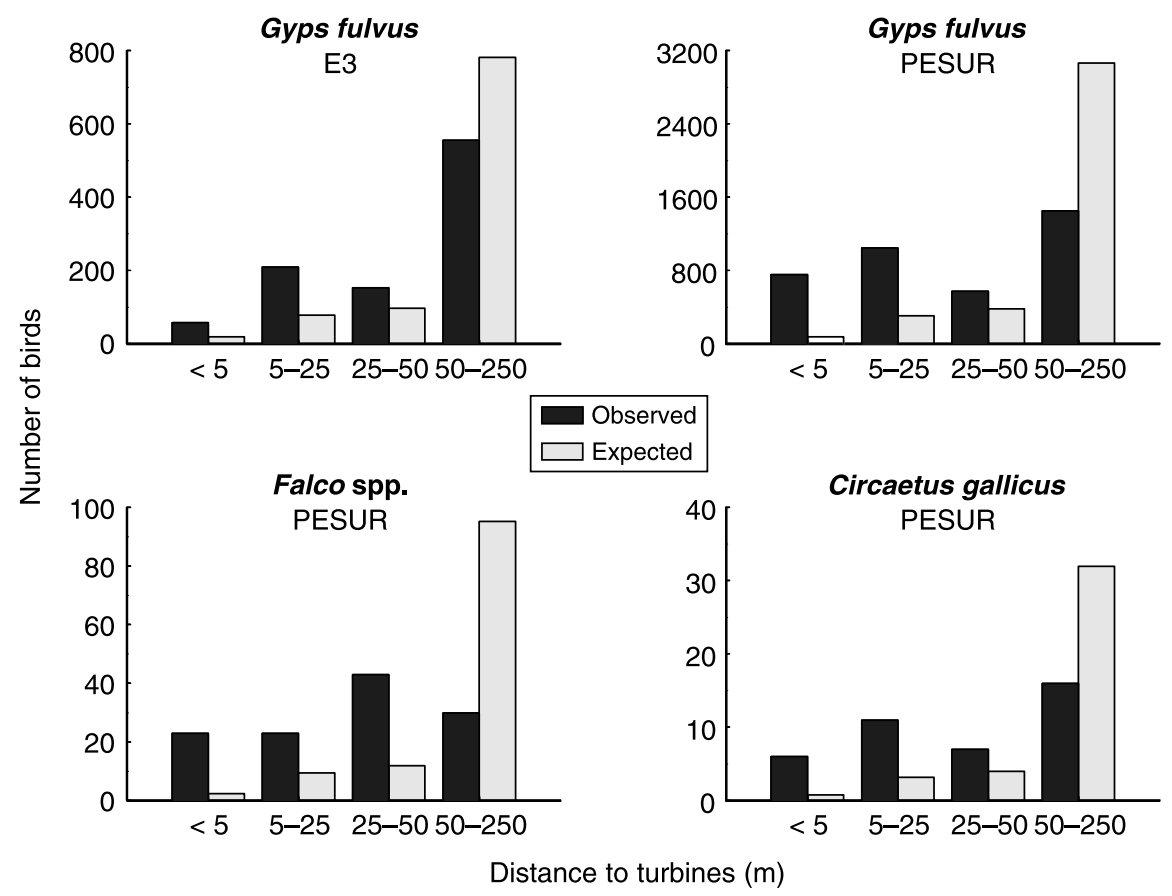

Fig. 2. The distribution of distances between observed birds and the line of turbines at PESUR and E3 wind farms. The number of birds expected to occur in each distance interval if they were evenly distributed within $250 \mathrm{~m}$ of turbines is also shown. Goodness-of-fit contingency table analysis: $G$. fulvus at E3 $(G=133 \cdot 1, P<0 \cdot 001, n=977), G$. fulvus at PESUR $(G=1699, P$ $<0 \cdot 001, n=3832)$, Falco spp. at PESUR $(G=79 \cdot 54, P<0 \cdot 001, n=119), C$. gallicus at PESUR $(G=15 \cdot 30, P=0 \cdot 002, n=40)$; d.f. $=3$ in all cases.

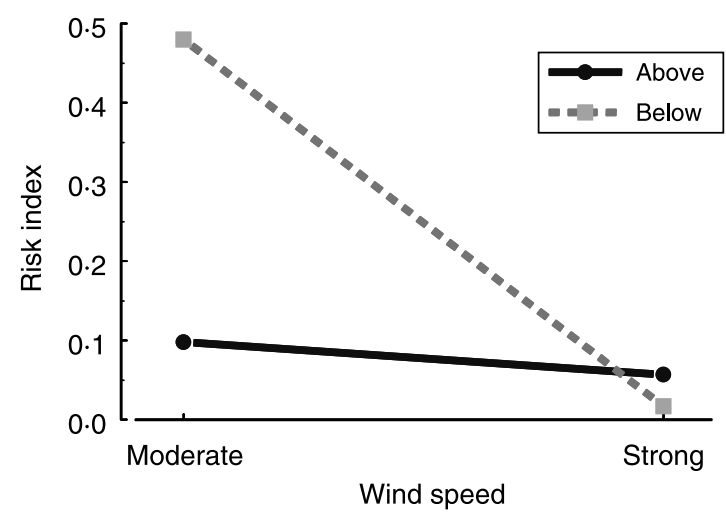

Fig. 3. The interaction between height of flight at first contact with the observation area and wind speed on the putative risk index for G. fulvus at PESUR wind farm. Range of speeds of light/moderate winds: $4 \cdot 6-12 \cdot 5 \mathrm{~m} \mathrm{~s}^{-1}$; strong winds: $>12 \cdot 5 \mathrm{~m} \mathrm{~s}^{-1}$.

flights $(0 \cdot 003)(G=23 \cdot 20$, d.f. $=2, P<0 \cdot 001)$. Finally, flights from below the blades (risk index 0.043) were twice as risky as flights coming from above (risk index $0 \cdot 022)$ but differences were not significant $(G=3 \cdot 26$, d.f. $=1, P=0 \cdot 07)$. No two-order interaction entered the final logistic regression model for E3 (Table 4b).

\section{Kestrels and short-toed eagle}

(C) 2004 British Ecological Society, Journal of Applied Ecology, 41,

$72-81$
Common kestrels and lesser kestrels Falco naumanni Fleischer were considered together because of the difficulty in distinguishing them at distance. One-hundred and twenty-five passes by kestrels (119 at PESUR and six at E3) and 49 by short-toed eagles Circaetus gallicus Gmelin (40 at PESUR and nine at E3; all in non-migratory flights) were recorded (Fig. 2). These species tended to fly closer to the ridge (and to the turbines) than expected from a regular distribution (Fig. 2). Most birds were seen hovering above the windward slopes while on hunting flights. On 10 other occasions kestrels were seen perched on lattice towers, while one short-toed eagle was once seen sitting on a meteorological tower. No avoidance of the turbines could be discerned.

\section{Other species}

Data were recorded for 9502 passes of other species on migratory flights. Most observations (91\%) were at PESUR as directional migratory flights seen at E3 mostly followed routes running further than $500 \mathrm{~m}$ from any turbine. No risk situation was detected after 829 bird sightings at E3. At PESUR, during the pre-breeding migration, 736 passes of soaring birds belonging to seven species were recorded. Out of the 78 observations within $5 \mathrm{~m}$ of the turbines, 73 occurred while the turbines were turned off because the wind was not strong enough. Therefore, the number of risk situations was negligible. During the post-breeding migration, 7937 soaring birds of nine species were seen in the vicinity of the wind farms. Risk situations were recorded for five species. The risk index was less than 0.03 for honey buzzards Pernis apivorus L., short-toed eagles, black kites and Egyptian vultures Neophron percnopterus L. (Table 5). These values were much smaller than risk 
Bird mortality at wind power plants
Table 4. Minimum adequate models describing the probability of occurrence of risk situations for griffon vultures at PESUR (a) and E3 (b). The intercept refers to the circling type of flight, flight height above the blades, and light and moderate wind (a) or light wind (b). Sign, coefficient and significance of the effects are all relative to levels included in the intercept

\begin{tabular}{|c|c|c|c|c|c|}
\hline Step & Coefficient & SE & $G$ & d.f. & $P$ \\
\hline \multicolumn{6}{|l|}{ (a) } \\
\hline Intercept & $-11 \cdot 15$ & $4 \cdot 13$ & & & \\
\hline 1 Strong wind & $-1 \cdot 09$ & $0 \cdot 21$ & $346 \cdot 3$ & 1 & $<0.001$ \\
\hline 2 Flight below the blades & $12 \cdot 39$ & $4 \cdot 14$ & $281 \cdot 1$ & 1 & $<0 \cdot 001$ \\
\hline 3 Straight flight & $9 \cdot 44$ & $4 \cdot 13$ & $784 \cdot 8$ & 2 & $<0 \cdot 001$ \\
\hline Slope flight & $-3 \cdot 75$ & $0 \cdot 22$ & & & \\
\hline 4 Flight below the blades and strong wind & $-3 \cdot 57$ & $0 \cdot 56$ & $69 \cdot 2$ & 1 & $<0 \cdot 001$ \\
\hline Deviance explained $(\%)$ & $41 \cdot 9$ & & & & \\
\hline \multicolumn{6}{|l|}{ (b) } \\
\hline Intercept & $-19 \cdot 93$ & $27 \cdot 59$ & & & \\
\hline 1 Straight flight & $15 \cdot 18$ & $27 \cdot 59$ & $30 \cdot 1$ & 2 & $<0 \cdot 001$ \\
\hline Slope flight & $-3 \cdot 77$ & $1 \cdot 13$ & & & \\
\hline 2 Flight below the blades & $16 \cdot 51$ & $27 \cdot 58$ & $96 \cdot 7$ & 1 & $<0.001$ \\
\hline 3 Moderate wind & 1.90 & $0 \cdot 65$ & $7 \cdot 9$ & 2 & $0 \cdot 019$ \\
\hline Strong wind & $-5 \cdot 45$ & $14 \cdot 68$ & & & \\
\hline Deviance explained $(\%)$ & $49 \cdot 8$ & & & & \\
\hline
\end{tabular}

indices for species having resident populations in the area, which at PESUR ranged between $0 \cdot 150$ and 0·198. Few black vultures Aegypius monachus L. were observed and all passes led to risk situations (Table 5).

\section{Discussion}

The distribution of collisions with wind turbines was clearly associated with the frequencies at which soaring birds flew close to rotating blades. Patterns of risky flights and mortality include a temporal component (deaths concentrated in some seasons), a spatial component (deaths aggregated in space), a taxonomic component (a few species suffered most losses) and a migration component (victims were usually species with resident populations rather than species occurring during migrations). This raises the question of what determines whether a bird approaches a turbine close enough to be hit by blades. We suggest that the mechanisms involved must be behavioural.

Bird abundance varies markedly with season. Kestrel density was highest during the post-fledging period, in July and August. Wintering vultures, which may be up to 10 times the number of residents (SEO/BirdLife 2001), sometimes join the local population for months. Therefore, the concentration of kestrel deaths in summer and vulture deaths in autumn-winter might support the hypothesis that the rate of wind turbine casualties increases with bird density (Musters, Noordervliet \& Ter-Keurs 1996; Osborn et al. 1998).

The seasonal pattern of vulture deaths may also be explained by flight behaviour. In common with other soaring birds, griffon vultures need vertical air currents to gain height (Bernis 1980; Pennycuick 1989, 1998). The availability and location of lifting currents varies seasonally. In summer, high temperatures allow the formation of thermals from valley bottoms, whereas in
Table 5. Putative risk index for soaring birds in migratory flights at PESUR during post-breeding migration

\begin{tabular}{lrrl}
\hline Species & Risk & No risk & Risk index \\
\hline Ciconia nigra & 0 & 71 & $0 \cdot 000$ \\
Ciconia ciconia & 0 & 4768 & $0 \cdot 000$ \\
Pernis apivorus & 3 & 123 & $0 \cdot 024$ \\
Milvus migrans & 46 & 2567 & $0 \cdot 018$ \\
Neophron percnopterus & 3 & 162 & $0 \cdot 018$ \\
Circaetus gallicus & 2 & 127 & $0 \cdot 016$ \\
Hieraetus pennatus & 0 & 57 & $0 \cdot 000$ \\
Aegypius monachus & 2 & 0 & $1 \cdot 000$ \\
Accipiter gentilis & 0 & 6 & $0 \cdot 000$ \\
Total & 56 & 7881 & $0 \cdot 007$ \\
\hline
\end{tabular}

winter lower temperatures make thermals scarcer. Birds are thus constrained to gain height with slope updrafts (Pennycuick 1989), whose force on most winter days may be insufficient to lift vultures well above the ridge, thereby exposing them to the turbines. In weak winds, other soaring birds, such as common buzzards Buteo buteo L. and short-toed eagles, often circled together with vultures in slope updrafts but did not closely approach the turbine blades and rarely collided with them. These species have lower wing loadings than vultures, and apparently make a more efficient use of the ascending currents, gaining altitude quicker and farther from the turbines.

Most vulture deaths were recorded at PESUR. At this wind farm, the number of vultures counted was $1 \cdot 5$ times larger, but the overall risk index was $3 \cdot 4$ times higher, than at E3. Therefore, the risk of collision at PESUR was higher than predicted from local differences in the relative abundance of vultures. The gentle and short slopes of PESUR may generate weak updrafts, especially in light winds, exposing circling vultures to the turbines once at the ridge, the point where wind strength
Journal of Applied

Ecology, 41,

$72-81$ 
is maximum (Pennycuick 1989). Such weak updrafts may have formed at the two turbine rows where both vulture corpses and risk situations aggregated. In strong winds at PESUR, or in light winds at the long and steep slopes of E3, lifts gained sustaining force and risk situations disappeared. Besides circling, straight flights below turbine level were risky because birds had to cross through the narrow space between two operating machines. It appears that vulture risk of mortality was mediated by flight behaviour, which in turn was determined by the interaction between wind and relief at specific locations.

The importance of local variation in wind behaviour as a potential predictor of vulture mortality was indirectly supported by the patterns of kestrel mortality. Common kestrels hover during hunting flights but do not depend upon lifting air currents to reach the mountain ridges. Accordingly, kestrel carcasses were less aggregated at PESUR. Almost all observations of kestrels were made at PESUR, especially in areas with open vegetation suitable for hunting. Open areas were rare at the mountain ridges of E3, where no kestrel casualties were recorded.

Kestrels sometimes perched on lattice towers, and griffon vultures frequently flew at close distance to the blades, or between two adjacent turning turbines. Indeed, the frequency of risk situations was higher than expected for all species, which indicates that turbines or towers were not actively avoided, as has been suggested by Orloff \& Flannery (1992) but in contrast with the conclusions of recent studies (Osborn et al. 1998; Guillemette \& Larsen 2002).

Lattice towers have been considered more dangerous to birds than tubular towers because many raptors use them for perching and, occasionally, nesting (Howell \& Noone 1992; Orloff \& Flannery 1992; Osborn et al. 1998). However, we found that deaths in lattice and tubular towers occurred with frequencies proportional to their respective occurrences. Most deaths and risk situations occurred in two rows at PESUR with little space between consecutive turbines. This windwall configuration (Orloff \& Flannery 1992) might force birds that cross at the blade level to take a risk greater than in less closely spaced settings. However, little or no risk was recorded for five turbine rows at PESUR having exactly the same windwall spatial arrangement of turbines. Therefore, we conclude that physical structures had little effect on bird mortality unless in combination with other factors.

Low visibility has been suggested as a causal factor of bird collisions at wind facilities. Winkelman (1985) observed that the probability of a collision occurring during a clear day was remote. However, collisions in our study area always occurred at times of good visibility. In addition, it was obvious that vultures adjusted their movements to avoid the revolving rotor blades.

Most wintering vultures were young birds (Griesinger 1996). Young vultures, however, were not especially prone to collisions compared with other age classes. Most common kestrels observed in summer at wind farms, as well as all common kestrels found dead, were juveniles.
Aggregation of juveniles during the post-fledging period is not unusual in common kestrels (Bustamante 1994). Higher numbers of juvenile kestrels at wind farms may be the simplest explanation of their vulnerability to turbines.

A fraction of the vultures that collided with wind turbines could be migratory or wintering birds. Other soaring-bird species, chiefly birds that occur in the study region in large numbers but only during their migration periods (e.g. white stork Ciconia ciconia L.), were rarely involved in risk situations and collisions. In 1994, the location of both wind farms was well away from the routes used by migratory birds, which, in addition, flew above the turbines. Such site-specific factors will not necessarily apply to other locations.

\section{CONCLUSIONS AND MANAGEMENT IMPLICATIONS}

Deaths per turbine and year in Tarifa were much larger than those recorded in similar studies elsewhere (Howell \& Noone 1992; Orloff \& Flannery 1992). Although the effect of turbine mortality on populations cannot be established, all species affected are listed as threatened or vulnerable in Spain (Blanco \& González 1992). Mitigation measures are thus necessary in order to minimize mortality. Our results indicate that the most sensible approach is to suspend the operation of the small number of turbines that cause most deaths only under the wind speeds that lead to risk situations.

A more general recommendation is that each new wind power facility project should include a detailed study of bird behaviour at the precise location where construction is proposed in order to identify species that are particularly vulnerable, which sites are intensively used, and hence the optimum turbine location.

\section{Acknowledgements}

The Consejería de Medio Ambiente, Junta de Andalucía, financed this study and SEO/BirdLife co-ordinated it. The authors and SEO/BirdLife are grateful to Enrique Aguilar for his help during the fieldwork, Mario Díaz for advice in the early stages of this study, and Colin J. Pennycuick, Brian A. Cooper, Magella Guillemette, and Kjetil Bevanger for their comments on the manuscript. Iñigo Sánchez helped with the experiment of carcass persistence. A. Rodríguez was supported by the Spanish Council for Scientific Research through a I3P-PC2001-1 grant. This paper contains the results of a report produced in 1995 by SEO/BirdLife entitled 'Incidencia de las plantas de aerogeneradores sobre la avifauna en el Campo de Gibraltar'.

\section{References}

Alonso, J.C., Alonso, J.A. \& Muñoz-Pulido, R. (1993) Señalización de líneas de alta tensión para la protección de la avifauna. Línea Valdecaballeros-Guillena. Red Eléctrica de España, Madrid, Spain. 
Bird mortality at wind power plants
Avery, M.L., Springer, P.F. \& Cassel, J.F. (1976) The effects of a tall tower on nocturnal bird migration - a portable ceilometer study. Auk, 93, 281-291.

Bernis, F. (1962) Sobre migración de nuestros paseriformes transaharianos. Ardeola, 8, 41-119.

Bernis, F. (1980) La migración de las aves en el Estrecho de Gibraltar. I. Aves planeadoras. Facultad de Biología, Universidad Complutense de Madrid, Madrid, Spain.

Blanco, J.C. \& González, J.L. (eds) (1992) Libro rojo de los vertebrados de España. ICONA, Madrid, Spain.

Bustamante, J. (1994) Behavior of colonial common kestrels (Falco tinnunculus) during the post-fledging dependence period in southwestern Spain. Journal of Raptor Research, 28, 79-83.

Byrne, S. (1983) Bird movements and collision mortality at a large horizontal axis wind turbine. Cal-Neva Wildlife Transactions, 1983, 76-83.

Crawley, M.J. (1993) GLIM for Ecologists. Blackwell Science, Oxford, UK.

Del Junco, O. \& Barcell, M. (1997) El buitre leonado en la provincia de Cádiz. Consejería de Medio Ambiente, Junta de Andalucía, Sevilla, Spain.

Faanes, C.A. (1987) Bird Behavior and Mortality in Relation to Power Lines in Prairie Habitats. Report No. 7. United States Department of Interior, Fish and Wildlife Service, Washington, DC.

Fernández-Cruz, M., Fernández, G., González, E. \& Paris, M. (1990) Estudio poblacional de las aves del Estrecho de Gibraltar. Planta Eólica del Sur, Madrid, Spain.

Ferrer, M., de la Riva, M. \& Castroviejo, J. (1991) Electrocution of raptors on power lines in southwestern Spain. Journal of Field Ornithology, 62, 181-190.

Finlayson, C. (1992) Birds of the Strait of Gibraltar. Poyser, London, UK.

Gill, J.A., Sutherland, W.J. \& Watkinson, A.R. (1996) A method to quantify the effects of human disturbance on animal populations. Journal of Applied Ecology, 33, 786-792.

Griesinger, J. (1996) Autumn migration of griffon vulture (Gyps fulvus) in Spain. Biología y conservación de las rapaces mediterráneas (eds J. Muntaner \& J. Mayol), pp. 401-410. Sociedad Española de Ornitología, Madrid, Spain.

Guillemette, M. \& Larsen, J.K. (2002) Postdevelopment experiments to detect anthropogenic disturbances: the case of sea ducks and wind parks. Ecological Applications, 12, 868-877.

Howell, J.A. \& Noone, J. (1992) Examination of Avian Use and Mortality at a US Windpower Development Site, Montezuma Hills, Solano County, California. Final Report. Solano County Department of Environmental Management, Fairfield, CA.

IDAE (1992) Manual de energía eólica. Cuadernos de Energías Renovables 4. Instituto para la Diversificación y Ahorro de la Energía, Madrid, Spain.

INM (1988) Mapa eólico nacional. Instituto Nacional de Meteorología, Madrid, Spain.

Janss, G.F.E. \& Ferrer, M. (1999) Avian electrocution on power poles: European experiences. Birds and Power Lines (eds M. Ferrer \& G.F.E. Janss), pp. 145-159. Quercus, Madrid, Spain.

Karlsson, J. (1983) Birds and Windpower. Report 1977-82. Report No. 84. United States Government.
Larsen, J.K. \& Madsen, J. (2000) Effects of wind turbines and other physical elements on field utilization by pink-footed geese (Anser brachyrhynchus): a landscape perspective. Landscape Ecology, 15, 755-764.

Moreau, R.E. (1972) The Palaearctic-African Bird Migration Systems. Academic Press, London, UK.

Musters, C.J.M., Noordervliet, M.A.W. \& Ter-Keurs, W.J. (1996) Bird casualties caused by a wind energy project in an estuary. Bird Study, 43, 124-126.

Negro, J.J. (1987) Adaptación de los tendidos eléctricos al entorno. Monografías Alytes, 1, 1-121.

Nelson, H.K. \& Curry, R.C. (1995) Assessing avian interactions with windplant development and operation. Transactions of the North American Wildlife and Natural Resources Conference, 60, 266-287.

Orloff, S. \& Flannery, A. (1992) Wind Turbine Effects on Avian Activity, Habitat Use, and Mortality in Altamont Pass and Solano County Wind Resource Areas (1989-91). Final Report. Planning Departments of Alameda, Contra Costa and Solano Counties and the California Energy Commission, BioSystems Analysis Inc., Tiburón, CA

Osborn, R.G., Dieter, C.D., Higgins, K.F. \& Usgaard, R.E. (1998) Bird flight characteristics near wind turbines in Minnesota. American Midland Naturalist, 139, 20-38.

Osborn, R.G., Higgins, K.F., Usgaard, R.E., Dieter, C.D. \& Neiger, R.D. (2000) Bird mortality associated with wind turbines at the Buffalo Ridge Wind Resource Area, Minnesota. American Midland Naturalist, 143, 41-52.

Pedersen, M.B. \& Poulsen, E. (1991) Avian Response to the Implementation of the Tjaereborg Wind Turbine at the Danish Wadden Sea. Studies on Danish Fauna Report 47. Denmark Institute of Ecological Studies, Kalø, Denmark.

Pennycuick, C.J. (1989) Bird Flight Performance. Oxford University Press, Oxford, UK.

Pennycuick, C.J. (1998) Field observation of thermals and thermal streets, and the theory of cross-country soaring flight. Journal of Avian Biology, 29, 33-43.

Pettifor, R.A., Caldow, R.W.G., Rowcliffe, J.M., GossCustard, J.D., Black, J.M., Hodder, K.H., Houston, A.I., Lang, A. \& Webb, J. (2000) Spatially explicit, individualbased, behavioural models of the annual cycle of two migratory goose populations. Journal of Applied Ecology, 37 (Supplement 1), 103-135.

Schadt, S., Revilla, E., Wiegand, T., Knauer, F., Kaczensky, P., Breitenmoser, U., Bufka, L., Cerveny, J., Huber, T., Stanisa, C. \& Trepl, L. (2002) Assessing the suitability of central European landscapes for the reintroduction of Eurasian lynx. Journal of Applied Ecology, 39, 189-203.

Scott, R.E., Roberts, L.J. \& Cadbury, C.J. (1972) Bird deaths from power lines at Dungeness. British Birds, 65, 273-286.

SEO/BirdLife (2001) Programa MIGRES. Seguimiento de la migración en el Estrecho. Año 2000. SEO/BirdLife, Madrid, Spain.

Winkelman, J.E. (1985) Bird impact by middle-sized wind turbines on flight behaviour, victims, and disturbance. Limosa, 58, $117-121$.

Winkelman, J.E. (1989) Birds and the Wind Park Near Urk: Collision Victims and Disturbance of Ducks, Geese and Swans. RIN Report 89/15. Rijksinstituut voor Natuurbeheer, Arnhem, the Netherlands.

Received 15 June 2003; final copy received 10 November 2003
(C) 2004 British

Ecological Society, Journal of Applied Ecology, 41,

$72-81$ 